\title{
Fate and Toxicity of Carbamazepine and Its Degradation By-Products During Coupling of Ozonation and Nanofiltration for Urban Wastewater Reuse
}

OPEN ACCESS

Edited by:

Daekyun Kim,

Clemson University, United States

Reviewed by:

Marta Llorca,

Institute of Environmental Assessment and Water Research (CSIC), Spain

Kang Xiao,

University of Chinese Academy of

Sciences, China

*Correspondence:

J. Mendret

julie.mendret@umontpellier.fr

Specialty section:

This article was submitted to

Organic Pollutants,

a section of the journal

Frontiers in Environmental Chemistry

Received: 20 October 2021 Accepted: 18 November 2021 Published: 09 December 2021

Citation:

Yacouba ZA, Lesage G, Mendret J, Zaviska F, Petit E and Brosillon S (2021) Fate and Toxicity of Carbamazepine and Its Degradation

By-Products During Coupling of Ozonation and Nanofiltration for Urban

Wastewater Reuse.

Front. Environ. Chem. 2:798785.

doi: 10.3389/fenvc.2021.798785

\author{
Z. Amadou Yacouba, G. Lesage, J. Mendret*, F. Zaviska, E. Petit and S. Brosillon \\ Institut Européen des Membranes, IEM, Univ Montpellier, CNRS, ENSCM, Montpellier, France
}

Occurrence of emerging organic micropollutants in water bodies and their effects are a concern related to quality of reused water. Advanced oxidation processes have demonstrated promising results to address this challenge. Nonetheless, these processes may lead to the generation of more toxic oxidation by-products. The aim of this study was to investigate the coupling of ozonation and nanofiltration (NF) applied to carbamazepine (CBZ). It consisted in monitoring the degradation and fate of CBZ and its subsequent by-products, their fate and toxicity. CBZ was completely degraded after 5 min of ozonation and six identified transformation by-products were formed: I (hydroxycarbamazepine), BQM [1-(2-benzaldehyde)-4-hydro-(1H, 3H)-quinazoline-2one], II (2-(1H)-quinazolinone), BaQM [1-(2-benzoic acid)-4-hydro- $(1 \mathrm{H}, \quad 3 \mathrm{H})$ quinazoline-2-one], BQD [1-(2-benzaldehyde)-(1H, 3H)-quinazoline-2,4-dione] and BaQD [1-(2-benzoic acid)-(1H, 3H)-quinazoline-2,4-dione]. Mineralization rate of ozonation never exceeded $12 \%$ even with high ozone dose. Bioassays with Vibrio fischeri revealed that $\mathrm{BQM}$ and $\mathrm{BQD}$ are responsible for toxicity. NF is able to remove total organic carbon with removal rate up to $93 \%$ at $85 \%$ of permeate recovery rate. CBZ and its different ozonation by-products were almost completely retained by NF, except the II, which had an MW slightly lower than the membrane molecular weight cutoff, for which the removal rate was still between 80 and $96 \%$ depending on the recovery rate.

Keywords: wastewater reuse, nanofiltration, ozonation, organic micropollutant, by-product, acute toxicity

\section{INTRODUCTION}

Domestic wastewater (DWW) reuse is increasingly considered a promising solution to the growing water scarcity in many areas around the world (Cirelli et al., 2012; Kellis et al., 2013; Lyu et al., 2016; Gude 2017). However, even for the most efficient conventional secondary treatment processes, which include membrane bioreactors (MBRs), some limitations have been pointed out regarding biorefractory contaminants, which might have adverse effects on the ecosystems and human health (Luo et al., 2014; Iorhemen et al., 2016; Majumder et al., 2019). For instance, various organic micropollutants (OMPs) are found widespread in MBR secondary effluent at concentration

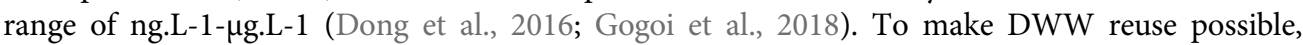


wastewater treatment plant (WWTP) effluent must thus undergo efficient and sustainable tertiary treatment processes (Po et al., 2005; Baawain et al., 2020).

Advanced oxidation processes (AOPs) are attractive solutions for post-treatment of DWW as those processes allow the elimination of a wide range of OMPs from wastewater. AOPs may also occasionally lead to the formation of more toxic byproducts (Le et al., 2016, 2017; Deng 2020a; Pohl et al., 2020). One of the most reactive oxidants after hydroxyl radicals $(\bullet \mathrm{OH})$ is ozone (Rekhate and Srivastava, 2020). Margot et al. (2013) and Guilloussou et al. (2020) have demonstrated the abilities of ozone to degrade the majority of pharmaceutical compounds in real DWW as a tertiary treatment (Margot et al., 2013; Guillossou et al., 2020). Bourgin et al. (2018) demonstrated removals higher than $80 \%$ for the 12 micropollutants used as indicator substances in the Swiss legislation throughout the processes of an entire WWTP upgraded with an ozonation step $(0.5 \mathrm{gO} / \mathrm{gC})$ (Bourgin et al., 2018). Different mechanisms and agents are involved during ozonation: combination of molecular ozone and byproducts, radicals from ozone self-decomposition or from the reaction of ozone with colloidal and dissolved organic mater (Huber et al., 2003; Ternes et al., 2003; Dodd et al., 2006; Ikehata et al., 2006; Snyder et al., 2006; Javier Benitez et al., 2009; Wert et al., 2009).

However, the mineralization of organic matter from secondary effluent by ozonation is rather low. Rosal et al., for instance, measured a total organic carbon (TOC) decrease of only $15 \%$ (Rosal et al., 2008; Deng 2020b; Dubowski et al., 2020). This incomplete TOC removal indicates the presence of by-products that can be more toxic than the parent molecules. Consequently, whatever the reuse made of the treated DWW, the environmental and human health risks may remain high because by-products may induce more severe environmental impacts than the targeted OMPs (Azaïs et al., 2017). Indeed, it has been proven that ozonation may generate toxicity. Notably, several studies reported increased in vitro and in vivo toxicity in the effluent of an ozone treatment (Völker et al., 2019). In addition, the literature suggests that an ozone treatment should only be implemented with a subsequent post-treatment to remove the by-products generated. However, considering the limited data available, and given that the reported performance in reducing toxicity differs significantly between studies, Volker et al. propose that further investigations are required to identify an optimal post-treatment.

As a solution to the management of these by-products and the associated toxicity, membrane filtration processes are highly promising. Nanofiltration (NF) and reverse osmosis (RO) processes are known to effectively separate small molecules such as OMPs through size exclusion, electrostatic interactions, hydrophobic interactions between solutes and solvent and membrane affinities and interactions. RO offers very high selectivity and OMPs rejection rates, but the low flux and high required pressure constitute its main drawbacks. As an alternative solution, NF was recently developed because it offers good selectivity and OMPs rejection rates at an acceptable permeate flux (Zhang et al., 2020). This method's main drawbacks are its propensity to fouling and the management of its generated concentrate usually representing $10-15 \%$ of feed water volume (Chon et al., 2011; Azaïs et al., 2014; Lan et al., 2018).

By coupling the ozonation and NF processes, the advantages of one process can be used against the drawbacks of the other (Ouali et al., 2020). For instance, the degradation ability of ozonation may be used to mitigate the fouling propensity of secondary effluent colloidal and dissolved organic matter (Yu et al., 2018). Vatankhah et al. (2018) have applied a pre-ozonation step before the nanofiltration of wastewater effluent and found that at a specific ozone dose of $0.2 \mathrm{mgO} 3 / \mathrm{mgC}$ showed a significant reduction in fouling compared to the nanofiltration with no pre-ozonation. Moreover, the selectivity and rejection capabilities of NF may be utilized to remove the degradation by-products generated by the ozonation process (Byun et al., 2015).

A pharmaceutical, carbamazepine (CBZ, an antiepileptic molecule), has been selected for this study due to its representativeness for bio-refractory emerging contaminants found widespread in WWTP secondary effluent, its hydrophobicity (Log Kow $>2$ ) and its high reactivity to ozone (Huber et al., 2003; Clara et al., 2005; Braeutigam et al., 2012; Pohl et al., 2020). The specific objectives of the present study are to evaluate the potential removal of CBZ ozonation by-products by $\mathrm{NF}$ and to estimate the acute toxicity evolution of this effluent through the coupling process. The degradation of CBZ has been monitored by some authors, but to date and to our knowledge, no study has been conducted on the fate and toxicity of its degradation by-products during a subsequent NF process.

\section{MATERIALS AND METHODS}

\subsection{Carbamazepine Solution}

As the organic matter of a real secondary effluent would react with ozone and interfere in chemical pathway determination, ultrapure water (UPW) was used as matrix for all the experiments (Papageorgiou et al., 2017). CBZ was purchased at Sigma-Aldrich and was of analytical grade, its physicochemical properties are shown in Table 1. In order to monitor the ozone-based degradation rate and determine low concentrations of $\mathrm{CBZ}$ and its by-products in permeate when a high rejection rate is achieved with the membrane, the UPW was spiked with $20 \mathrm{mg} . \mathrm{L}^{-1}$ of $\mathrm{CBZ}$ before the reaction.

\subsection{Ozonation Setup}

The ozonation lab-scale pilot consists of a glass stirred batch reactor $\left(\mathrm{V}_{\text {reactor }}=3 \mathrm{~L}\right)$ under thermostatic control $\left(20{ }^{\circ} \mathrm{C}\right)$ continuously fed by an ozone generator (BMT $803 \mathrm{~N}$ ) from a lab-grade pure oxygen tank (Figure 1). Before diffusion in the reactor, the ozone was diluted with oxygen to achieve a gas flow of $60 \mathrm{NL} \mathrm{h}^{-1}$ and introduced from the bottom of the reactor through a porous diffuser. An ozone gas analyzer (BMT 964) was utilized to monitor the gas ozone concentration $\left(\left[\mathrm{O}_{3}\right]_{\text {gas,in }}\right)$ after dehumidification by a BMT dehumidifier. The chemical pathway was determined for two different ozone concentrations (5 and $30 \mathrm{gO}_{3} / \mathrm{Nm}^{3}$ in the inlet gas) and 
TABLE 1 | Physicochemical characteristics of carbamazepine.

\begin{tabular}{|c|c|c|c|c|c|}
\hline Compound & MW g.mol ${ }^{-1}$ & $\begin{array}{l}\text { Kinetic rate } \\
\text { constant with } \\
\text { ozone at } \\
\text { pH } 7 \\
\text { L.mol } \\
-1 . s^{-1}\end{array}$ & Log-Kow & $\begin{array}{l}\text { Charge at } \\
\mathrm{pH} 7\end{array}$ & Molecular structure \\
\hline Carbamazepine (CBZ) $\mathrm{C}_{15} \mathrm{H}_{12} \mathrm{~N}_{2} \mathrm{O}$ & 236.3 & $3.0 \times 10^{5 a}$ & $2.45^{\mathrm{b}}$ & Neutral & \\
\hline
\end{tabular}

monitored for $30 \mathrm{~min}$ of contact time. The indigo method was employed to determine the dissolved ozone concentration (Bader and Hoigné 1981). Two electro valves connected to a computer were used to apply the desired concentration of the oxygen/ozone mix. During the reaction, a mechanical stirrer was utilized to homogenize (400 rpm) and increase the ozone dissolution rate in the solution. A recirculating pump was used for sampling.

\subsection{Nanofiltration Setup 2.3.1 Nanofiltration Membrane Selection and Characterization}

The aromatic polyamide membrane NF-90 (Dow-Filmtec, Midland, MI) was selected for use in the experiments. This membrane is considered a "tight" NF membrane with an estimated MWCO of around $150 \mathrm{Da}$, which seems appropriate for the retention of CBZ and most of its degradation by-products (Azaïs et al., 2017). Before experimentation, the membrane was first soaked in UPW to remove preservative compounds and then compacted at 18 bars for at least $1 \mathrm{~h}$ or until stability of the flux was reached. Each NF-90 membrane used in this study was characterized in terms of permeability and sodium chloride rejection. The mean initial permeability and $\mathrm{NaCl}$ rejection at 10 bars are respectively $8.4 \pm 1.0 \mathrm{~L} \mathrm{~h}^{-1} \mathrm{~m}^{-2}$ bar $^{-1}$ and $88 \pm 4 \%$. The whole ozonation nanofiltration set-up is described elsewhere (Amadou Yacouba et al., 2021).

\subsubsection{Cross-Flow Nanofiltration Unit}

An Osmonics Sepa CF II cell (Sterlitech Corp.) was used to conduct the filtration experiments utilizing flat sheet membrane coupons with an effective membrane area of $140 \mathrm{~cm}^{2}$. A pump (Hydra-Cell, Wanner Engineering, Inc.) was used to feed the membrane module with the solution from a $16 \mathrm{~L}$ feed vessel. A cryothermostat (F32, Julabo) maintained the feed at constant temperature $\left(20 \pm 1^{\circ} \mathrm{C}\right)$ to prevent an increase in liquid flow temperature. The transmembrane pressure (TMP) was set at 10 bars using a micrometric pressure control valve located on the retentate outlet. The experiments were performed at a crossflow velocity $\left(\mathrm{v}_{\mathrm{T}}\right)$ of $0.5 \mathrm{~m} \mathrm{~s}^{-1}$ with a medium foulant spacer, 47 Mil $(1.194 \mathrm{~mm})$. The effect of permeate recovery on the NF membrane efficiency was examined at different water recovery rates $(\mathrm{Y})$ corresponding to $\sim 0,15,40,60$ and $85 \%$.

Before the experiment, the feed water was placed in the storage tank and recirculated for $24 \mathrm{~h}\left(\mathrm{v}_{\mathrm{T}}=0.5 \mathrm{~m} \mathrm{~s}^{-1}\right)$ without TMP to ensure that compound adsorption onto the pipes and membrane had reached a steady state. The volume of the collected samples for the different analyses was considered in the apparent rejection calculation.

\subsection{Evaluation of the Nanofiltration and Ozonation System Performances} 2.4.1 Non-targeted Analyses and Confirmation of the Identified Transformation Products

By-products were identified during the ozonation of $\mathrm{CBZ}$ in an UPW matrix based on the study of Azaïs et al. (Azaïs et al., 2017). To establish the chemical pathway, the experiments were first run under an ozone concentration in the inlet gas phase of $5 \mathrm{~g} / \mathrm{Nm}^{3}$. Analyses were performed by liquid chromatography tandem high-resolution mass spectrometry using a time-of-flight mass spectrometer (LCTOF-MS) to identify the maximum of unknown by-products. The transformation products monitoring was conducted based on area of spectrum. The LC-TOF-MS analyses were performed using an Acquity H-Class equipped with a Phenomenex Kinetex C18 column $(100 \mathrm{~mm} \times 2.1 \mathrm{~mm}, 1.7 \mu \mathrm{m})$ maintained at $30^{\circ} \mathrm{C}$. Highresolution electrospray ionization mass spectrometry (HR-ESI-MS) data was acquired in positive or negative ion mode on a SYNAPT G2-S (Waters Corporation, Manchester, United Kingdom) equipped with an ESI source. The resolution for the standard Leucine Enkephalin $(\mathrm{MH}+=556.27)$ was 40 0000. The acquisitions were made under the following conditions: capillary voltage $3000 \mathrm{~V}$; cone voltage $20 \mathrm{~V}$; dry gas temperature $140^{\circ} \mathrm{C}$; desolvation temperature $=450^{\circ} \mathrm{C}$; dry gas flow, $1000 \mathrm{~L} \mathrm{~h}^{-1}$ using nitrogen as nebulizer gas; pressure $=6.5$ bars. A sample volume of $10 \mu \mathrm{L}$ was injected with a mobile phase flow rate of $0.5 \mathrm{ml} \mathrm{min}^{-1}$. The mobile phase was composed of a mixture of eluent A (milliQ water $+0.1 \% \mathrm{HCOOH}$ ) and $\mathrm{B}$ (acetonitrile $+0.1 \% \mathrm{HCOOH}$ ). The gradient consisted of $0-14 \mathrm{~min}: 100 \% \mathrm{~A}, 15-17 \mathrm{~min}: 100 \% \mathrm{~B}$, 17.1-20 min: $100 \%$ A. $1 \mathrm{ng} \mu \mathrm{L}^{-1}$ of Leucine Enkephalin was used as standard for internal calibration.

Collision-induced dissociation in the triple quadrupole was utilized to fragment and identify the selected by-products. The TOF analyzer (LC-Q-TOF-MS/MS) was used to measure the molecular masses of the fragments generated through a collision energy ranging from 15 to $40 \mathrm{eV}$ for each $\mathrm{MS} / \mathrm{MS}$ spectrum recorded. The so-obtained fragments were used to propose structural formulas for the selected degradation by-products. The proposed chemical structure was confirmed using the 


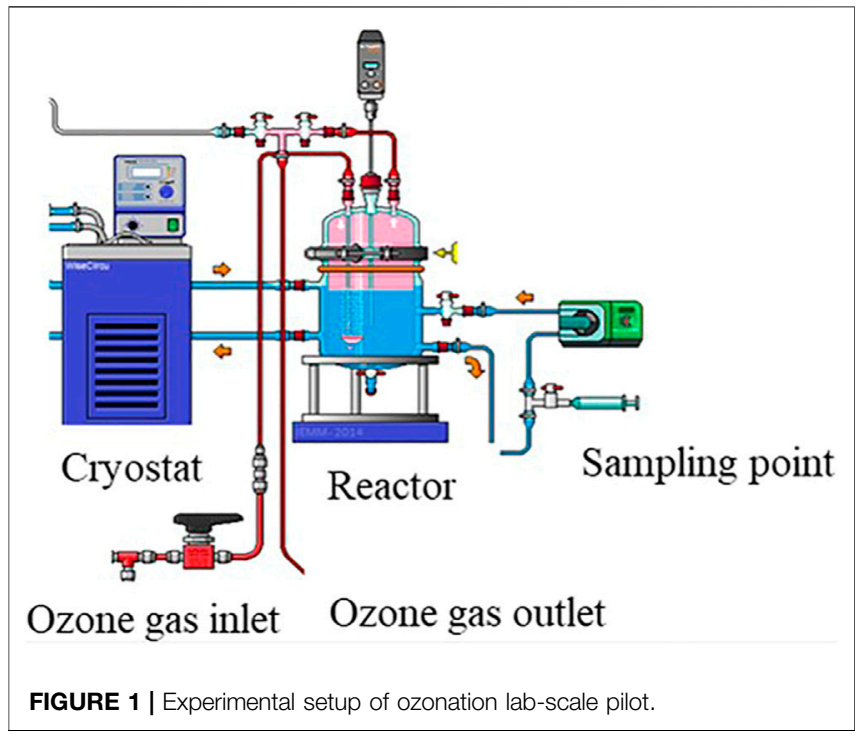

Waters mass fragment software. Following these analyses, a summary of the detected masses, retention times, empirical formulas and developed structures was established for each by-product. The identified by-products were selected to be tracked during the ozonation, and the kinetics of their appearance and degradation were assessed. Thereafter, the removal rate by NF of each by-product was monitored.

The instrument quantification limit (IQL) and the instrument detection limit (IDL) were determined according to a method of detection and quantification limits assessment based on a signal to noise of 3 and 10 for five replicates. IDL and IQL of CBZ in UPW were found to be $3.0 \mu \mathrm{g} . \mathrm{L}^{-1}$ and $9.9 \mu \mathrm{g} . \mathrm{L}^{-1}$ respectively.

\subsubsection{Global Indicator for Pollution Monitoring \\ 2.4.2.1 Total Organic Carbon Monitoring}

The mineralization extent was monitored during the ozonation of UPW doped with $20 \mathrm{mg} . \mathrm{L}^{-1}$ of CBZ though the TOC measurement using a TOC-VCSN Shimadzu analyzer (Shimadzu Japan). Same method has been applied to permeate and retentate flux during NF experiments to assess TOC concentrations.

\subsubsection{Toxicity Assessment}

Acute toxicity was monitored using a Microtox Model 500 analyzer with the Microtox Omni software (Modern Water Inc.). This analysis consisted in measuring the effect of the liquid samples on the bioluminescent marine Gram-negative strain bacteria Vibrio fischeri NRRL B-11177. During its cellular metabolism, this bacterium emits luminescence that could be reduced by the presence of toxic elements. Bioluminescence is therefore a very good indicator of the state of the bacterium and thus of the global toxicity of the sample. The acute toxicity assessment of the samples was performed using the $81.9 \%$ screening test for the determination of the removal kinetics during ozonation and the $45 \%$ screening test for removal evaluation in NF. The $81.9 \%$ (or 45\%) is the sample concentration after dilution by adding a $22 \% \mathrm{NaCl}$ solution, which was intended to simulate the saline conditions required

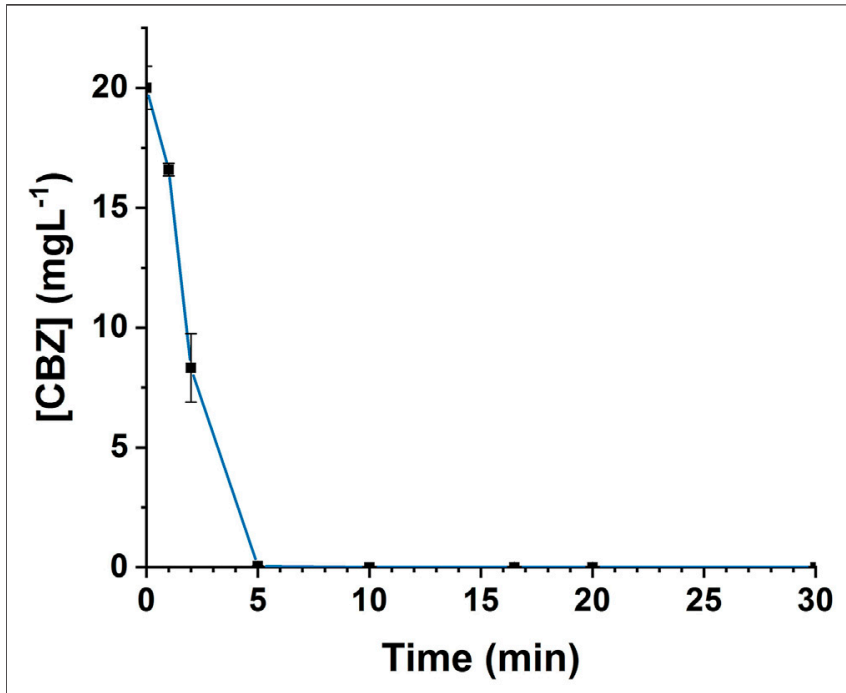

FIGURE 2 | Evolution of CBZ concentration during ozonation: initial concentration of $\mathrm{CBZ}=20 \mathrm{mgL}^{-1}$, Vreactor $=3 \mathrm{~L}$, Vstir $=400 \mathrm{rpm},\left[\mathrm{O}_{3}\right]$ gas $=5$ $\mathrm{gO}_{3} / \mathrm{Nm}^{3}$.

for the marine bacteria metabolism reactivation and thus for luminescence emission.

Before measuring the bacterial luminescence, the $\mathrm{pH}$ of the samples was adjusted to between 6.5 and 7.5. Further details regarding toxicity determination are provided in previous studies (Le et al., 2016; Azaïs et al., 2017; Le et al., 2017; El Kateb et al., 2019).

Even in the absence of any toxicity, the luminescence may vary over time due to experimental conditions. Therefore, this variability $R(t)$ was monitored through a control sample composed of $2 \% \mathrm{NaCl}$ in ultrapure water. $R(t)$ was calculated according the following equation:

$$
R(t)=\frac{L u(C t l)(t)}{L u(C t l)(t=0)}
$$

where $\mathrm{Lu}(\mathrm{Ctl})(t)$ is the intensity of the luminescence emitted by the bacteria after a given contact time (5 min or $15 \mathrm{~min}$ ), with the control solution in arbitrary units (AU), and $L u(C t l)(t=0)$ is the initial intensity of the luminescence emitted by the bacteria before the addition of the control solution (AU). The corrected inhibition rate $I(t)$ intrinsically attributed to the sample toxicity is then calculated using Eq. 2 and expressed in percentage:

$$
I(t)=\left(\frac{L u(\text { sample })(t)}{R(t) \times L u(\text { sample })(t=0)}\right) \cdot 100
$$

where $L u$ (sample) $(t)$ is the intensity of the luminescence emitted by the bacteria after a $t=5 \mathrm{~min}$ or $t=15 \mathrm{~min}$ of contact with a sample (AU), and $L u$ (sample) $(t=0)$ is the initial intensity of the luminescence emitted by the bacteria before the addition of the sample (AU).

The evolution of toxicity was monitored in the liquid bulk during the ozonation process and in the permeate and retentate brines of NF and was discussed in regard to the appearance and disappearance of degradation by-products as well as their removal rates by ozonation and NF. 


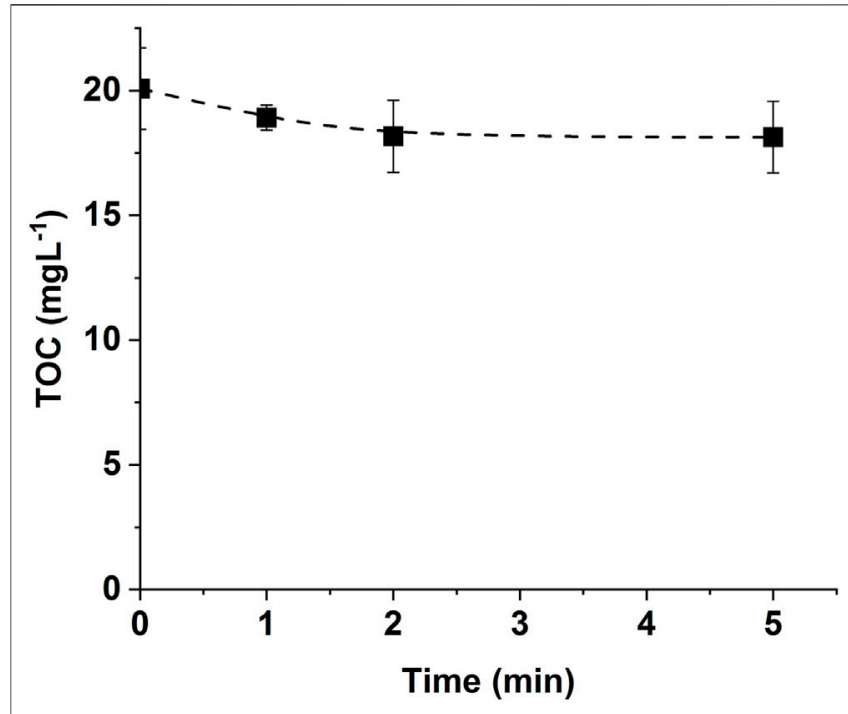

FIGURE 3 | Evolution of TOC during CBZ ozonation in UPW [CBZ $]_{0}=$ $20 \mathrm{mgL}^{-1}$, Vreactor $=3 \mathrm{~L}$, Vstir $=400 \mathrm{rpm},\left[\mathrm{O}_{3}\right]$ gas $=30 \mathrm{gO}_{3} / \mathrm{Nm}^{3}$.

\section{RESULTS AND DISCUSSION}

\subsection{Performance of Ozonation Process 3.1.1 Monitoring Carbamazepine Degradation}

Before the chemical pathway of CBZ was determined, its ozonebased degradation was first monitored (Figure 2).

As can clearly be seen in Figure 2, the CBZ is highly reactive to ozone and was completely degraded in the first $5 \mathrm{~min}$ period that corresponds to a specific transferred ozone dose of $2.48 \mathrm{mgO}_{3} /$ $\mathrm{mgC}$. In a previous study, Huber et al. (2003) determined a high reactivity coefficient $\left(3.0 \times 10^{5} \mathrm{~L} \mathrm{~mol}^{-1} \cdot \mathrm{s}^{-1}\right)$ for CBZ in pure aqueous solution using Milli-Q purified water.

\subsubsection{Mineralization of Carbamazepine During Ozonation}

The mineralization rate of CBZ by ozonation was monitored concomitantly to its degradation and is presented in Figure 3.

Figure 3 displays a very weak mineralization rate of CBZ during ozonation. In fact, as revealed by other researchers, the ozonation process is known for its inefficiency in reducing TOC (Byun et al., 2015). This process is known to degrade and fragmentize the mother molecules to transformation byproducts. Generally, there is a significant change in chemical oxygen demand and not in TOC concentration. During the present experiments, the mineralization never exceeded $12 \%$, especially during the first $5 \mathrm{~min}$ of ozonation contact time, even with a very high applied ozone gas concentration.

\subsubsection{Chemical Pathway of Carbamazepine During Ozonation}

Based on previous studies of the chemical pathway of CBZ degradation by AOPs $\left(\mathrm{O}_{3}\right.$, UV $+\mathrm{H}_{2} \mathrm{O}_{2}$, Mn (VII), Fe (VI)) and the kinetics of $\mathrm{CBZ}$ and its by-products, the following assumptions were made (Andreozzi et al., 2002; Vogna et al., 2004; Hu et al., 2009; Azaïs et al., 2017; Pohl et al., 2020). As soon as the ozone was injected into the reactor, the degradation of the CBZ began concomitantly with by-products formation. The byproduct "I" (hydroxycarbamazepine, $\mathrm{m} / \mathrm{z}=253.1$ ) was produced by the hydroxylation of the aromatic rings of CBZ, while 1-(2benzaldehyde)-4-hydro-( $1 \mathrm{H}, 3 \mathrm{H}$ )-quinazoline-2-one (BQM, m/z $=251.08)$ was formed from the CBZ intra-molecular reactions with molecular ozone and rearrangements according to the Criegee mechanism (Doll and Frimmel 2005; McDowell et al., 2005; Azaïs et al., 2017). As BQM was supposed to weakly react with molecular ozone, with second-order rate constant $\left(\mathrm{kO}_{3} \sim\right.$ $4 \mathrm{M}^{-1} \mathrm{~s}^{-1}$ ), it has predominantly reacted with hydroxyl radicals to form 1-(2-benzaldehyde)-(1H, 3H)-quinazoline-2,4-dione (BQD, $\mathrm{m} / \mathrm{z}=267.10)$ (McDowell et al., 2005). Azaïs et al. suggested that the formation of 1-(2-benzoic acid)- $(1 \mathrm{H}, 3 \mathrm{H})$ quinazoline-2,4-dione $(\mathrm{BaQD}, \mathrm{m} / \mathrm{z}=283.07)$ was due to a slow reaction of $\mathrm{BQD}$ with molecular ozone $\left(\mathrm{kO}_{3} \sim 1 \mathrm{M}-1 \mathrm{~s}-1\right)$ (Azaïs et al., 2017). 1-(2-benzoic acid)-4-hydro-(1H, 3H)-quinazoline2-one ( $\mathrm{BaQM}, \mathrm{m} / \mathrm{z}=267.10)$ with a mass similar to that of $\mathrm{BQD}$ was another compound that probably derives from $B Q M$ reaction with either a molecular ozone or hydroxyl radicals (Hübner et al., 2014). Another compound "II," a quinazoline (2-(1H)quinazolinone $)(\mathrm{m} / \mathrm{z}=147.06)$, was also detected. It was assumed to have formed as a result of the degradation of BQM and/or BaQM (McDowell et al., 2005; Azaïs et al., 2017). The overall oxidation pathway for CBZ is proposed in Figure 4.

\subsubsection{Monitoring of Carbamazepine Degradation By-Products}

During the experiment, the identified CBZ by-products were monitored along with ozonation time, and their relative concentrations, expressed in terms of area of UPLC/MS, were compared. Area of detection for each compounds were used because no commercial standards were available to quantify the concentration of the by-products in water. The normalization (A/ Amax) was calculated with the maximum value of the area (Amax) of each by-product as reference. The evolution of CBZ ozone-based degradation by-products is presented in Figure $\mathbf{5}$ for an initial CBZ concentration of $20 \mathrm{mgL}^{-1}$.

The results displayed in Figure $\mathbf{5}$ are highly concordant with those presented in Figure 4. After the launching of the reaction, the CBZ is immediately degraded. The ozonation of CBZ led to the formation of by-products I and BQM. While decreasing, the $\mathrm{BQM}$ seemed to be transformed into by-products II, $\mathrm{BaQM}$ and $\mathrm{BQD}$, which concomitantly yields the BaQD.

As the areas of different by-products are higher at $5 \mathrm{~min}$ of degradation time, the contact time was set to $5 \mathrm{~min}$ of reaction during the ozonation of $\mathrm{CBZ}$ to facilitate tracking the transformation by-products in subsequent NF processes.

\subsubsection{Monitoring of Toxicity During Ozonation}

During the chemical pathway determination, the toxicity evolution was also monitored. The aim was to link the toxicity trends observed to the appearance and disappearance of 


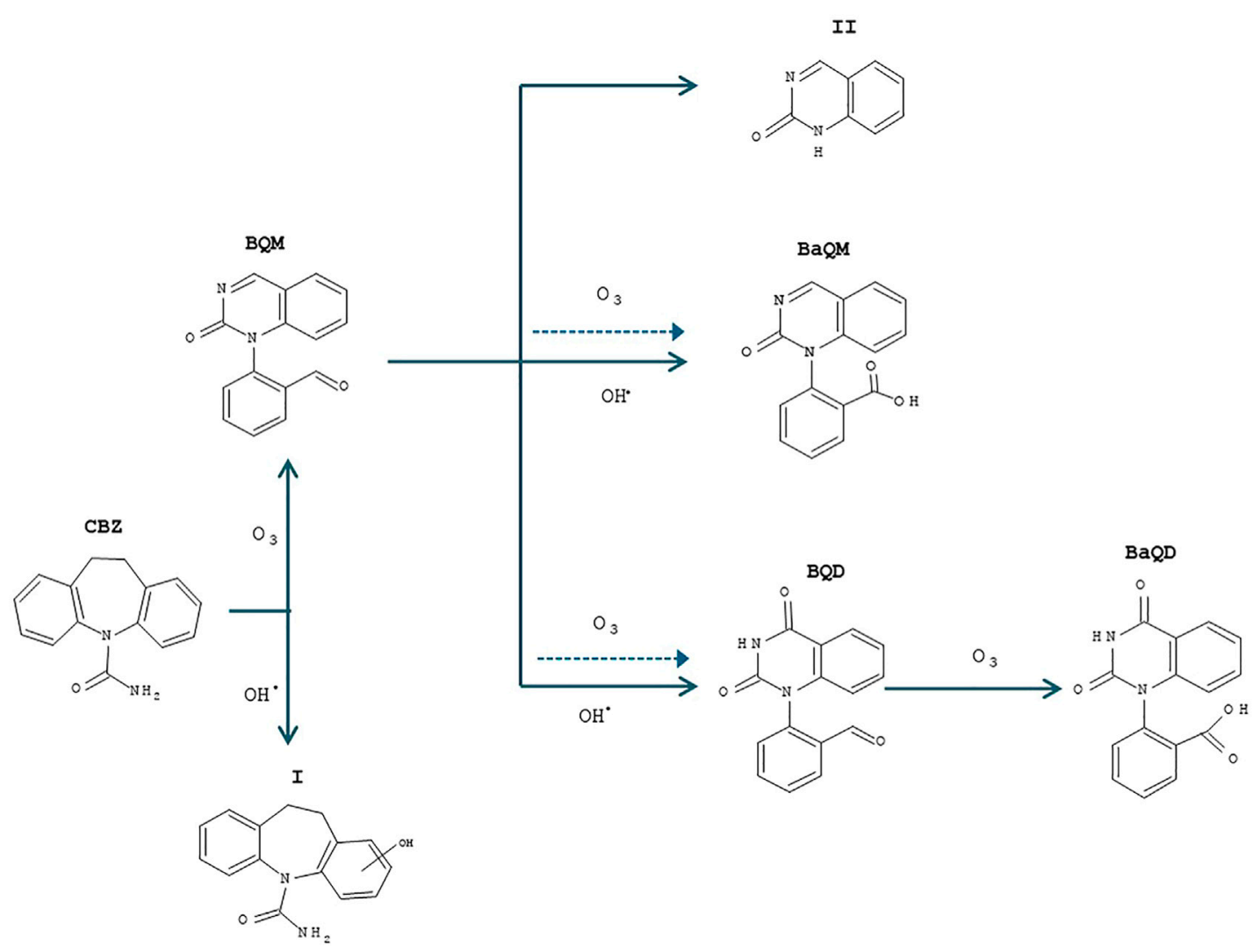

FIGURE 4 | Chemical pathway of CBZ during ozonation process $[\mathrm{CBZ}]_{0}=20 \mathrm{mgL}^{-1}$, Vreactor $=3 \mathrm{~L}, \mathrm{Vstir}=400 \mathrm{rpm},\left[\mathrm{O}_{3}\right] \mathrm{gas}=30 \mathrm{gO} / \mathrm{Nm}^{3}, \mathrm{~T}_{\text {reaction }}=30 \mathrm{~min}$. Adapted from Azais et al. (2017).

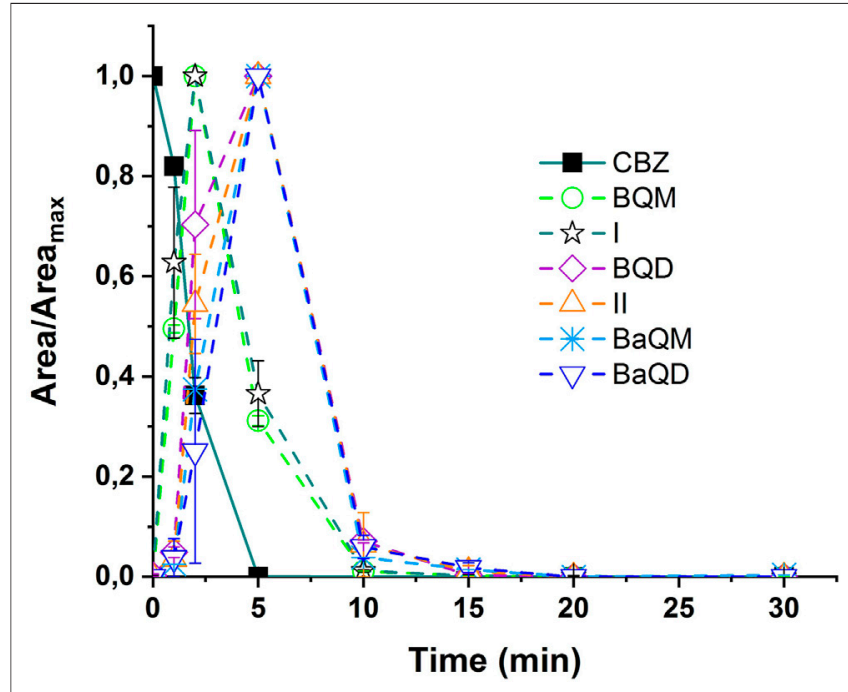

FIGURE 5 | Relative evolution of the normalized areas of CBZ and its ozonation by-products during ozonation of UPW doped with CBZ [CBZ $]_{0}=$ $20 \mathrm{mgL}^{-1}$, Vreactor $=3 \mathrm{~L}$, Vstir $=400 \mathrm{rpm},\left[\mathrm{O}_{3}\right]$ gas $=30 \mathrm{gO}_{3} / \mathrm{Nm}^{3}$. degradation by-products and then to identify the most toxic kinds. The results are presented in Figure 6.

Initially, with only $\mathrm{CBZ}$ in the solution, the toxicity level is about $15-20 \%$, indicating that the acute toxicity of the mother compound is relatively low. After 1-2 min of ozonation contact time, the toxicity increases to between 70 and $84 \%$ indicating the presence of relatively highly toxic compounds. This increase in the toxicity is consistent with the formation and predominance of BQM (1-(2-benzaldehyde)-4-hydro- $(1 \mathrm{H}, 3 \mathrm{H})$-quinazoline-2one) and BQD (1-(2-benzaldehyde)- $(1 \mathrm{H}, 3 \mathrm{H})$-quinazoline-2,4dione) in the solution, while the CBZ drastically decreases (Figure 5). The third stage in the toxicity trends, occurring after around 5 minutes of degradation contact time, consists in a decrease to the values in the range between 32 and $35 \%$ of $\mathrm{V}$. fischeri bioluminescence inhibition. This drop in the toxicity matches with a decrease in the concentration of BQM and the formation of further by-products, which are likely less toxic than BQM. These assumptions were confirmed by a recent study conducted by Pohl et al., who examined the in vivo individual and mixture toxicity in zebrafish (Danio rerio) of CBZ and its ozonation by-products (Pohl et al., 2020). In fact, their results confirm that the toxicity of the ozonated solution is mainly due 


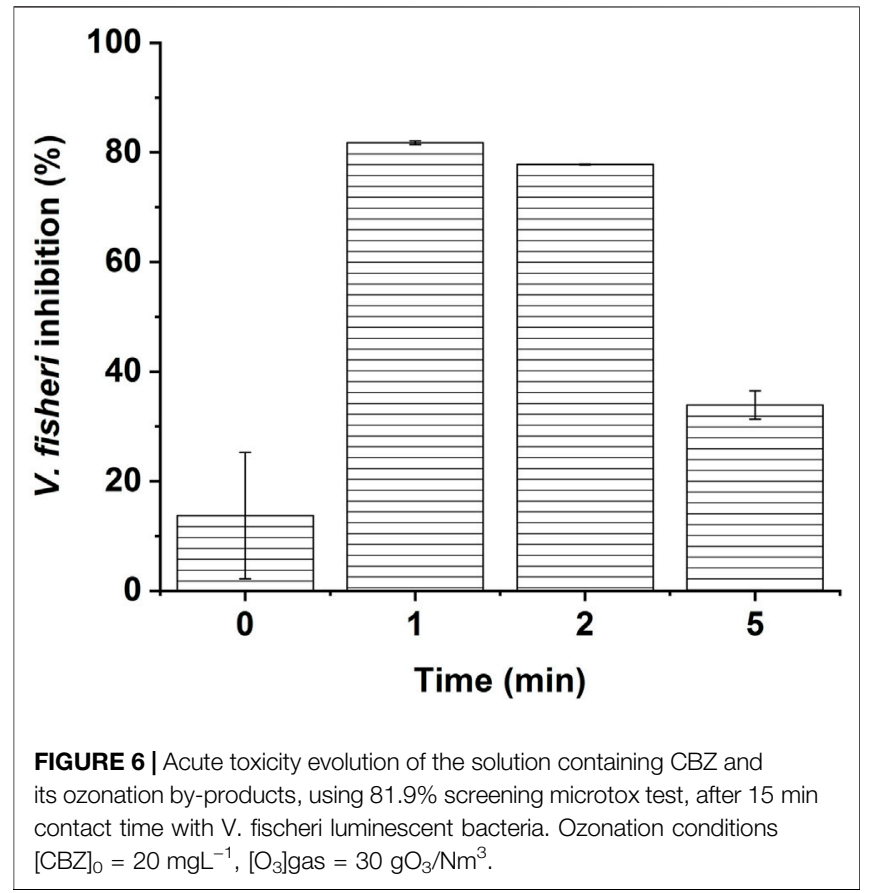

to BQM and BQD, which both completely disappeared after 15 min of ozonation in the experimental conditions of our study (Figure 5). These results reveal that the ozonation reaction duration is an important parameter to treat DWW with ozone without increasing the toxicity of the effluent.

\subsection{Performance of Nanofiltration System}

The performance of the NF system has been evaluated for both ozonated and non-ozonated effluent, taking into account the permeate flux and the $\mathrm{CBZ}$ and its by-products retention. The experiments were conducted over a period of $15-25 \mathrm{~h}$ in order to reach a water recovery rate of at least $85 \%(\mathrm{Y}=85 \%)$.

\subsubsection{Permeate Flux Evolution}

During the NF experiments, the evolution of the permeate flux was monitored for both ozonated and non-ozonated CBZ solution. The results are presented in Figure 7.

The permeate flux evolution displays a $20 \%$ decrease for both ozonated and non-ozonated matrixes. This drop in permeate flux is due to the CBZ and its by-products. After ozonation of the solution, the flux evolution was slightly (but not significantly) improved as the ozonation might not have mineralized the TOC but may instead have just transformed the CBZ into lower molecular weight by-products.

\subsubsection{Removal Performance During Nanofiltration Process}

\subsubsection{Removal of Total Organic Carbon}

Since all the experiments were run in UPW matrix, the measured organic carbon concentrations are due to the CBZ or its byproducts. The TOC concentrations were determined in both retentate and permeate streams along with the recovery rate and are presented in Figure 8.

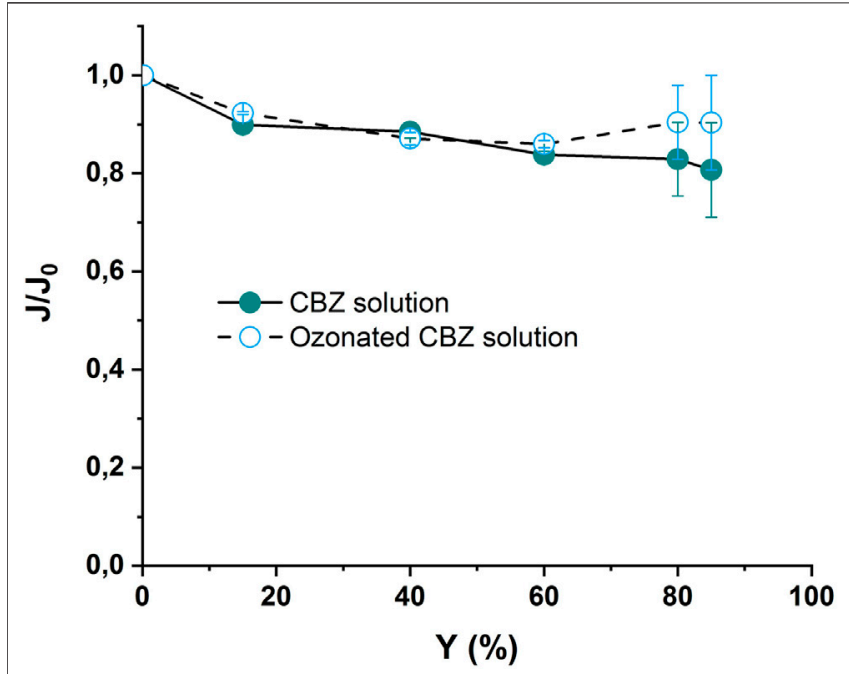

FIGURE 7 | Evolution of permeate flux versus recovery rate during NF experiments applied to ozonated and non-ozonated CBZ solutions using UPW matrix, NF-90 membrane, TMP $=10$ bars, $v t=0.5 \mathrm{~m} \mathrm{~s}^{-1}, \mathrm{Y}=0.1,15$, 40,60 and $85 \%$. Ozonation conditions $[\mathrm{CBZ}]_{0}=20 \mathrm{mgL}^{-1},\left[\mathrm{O}_{3}\right] \mathrm{gas}=30$ $\mathrm{gO}_{3} / \mathrm{Nm}^{3}, \mathrm{~T}_{\text {reaction }}=5 \mathrm{~min}$.

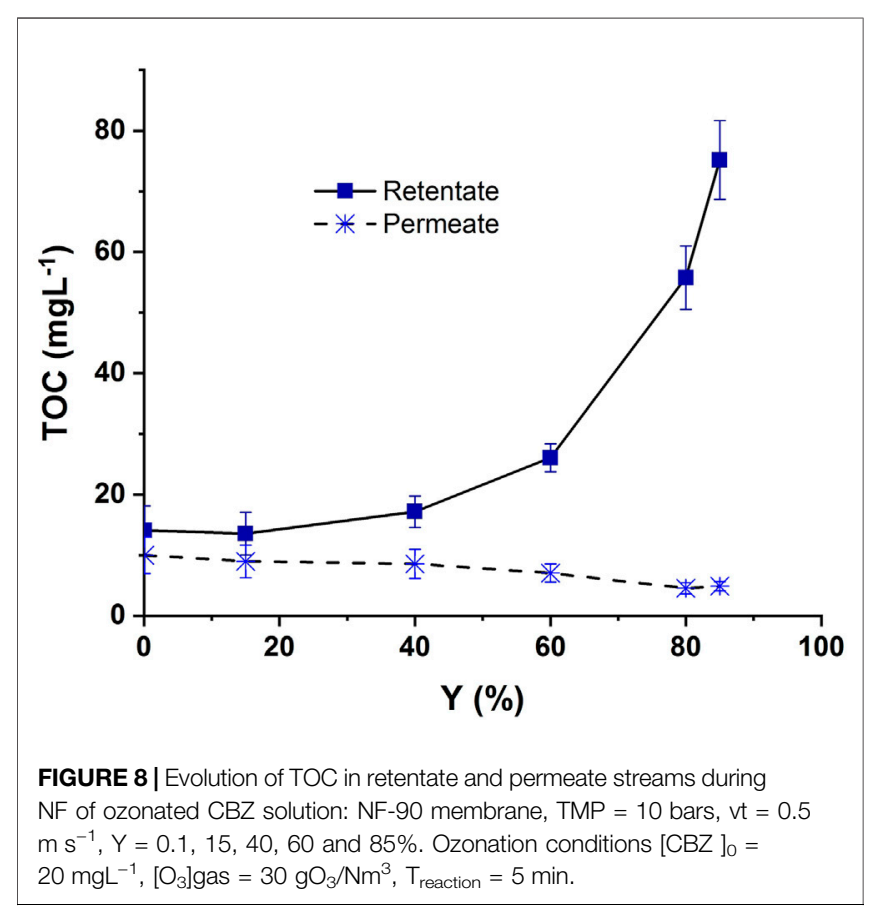

The TOC value was around $14 \mathrm{mgL}-1$ in the retentate and around $10 \mathrm{mgL}-1$ in the permeate streams at the beginning of the experiment. As the recovery rate rose, the TOC value increased in the retentate and slightly decreased in the permeate because the membrane was becoming fouled, which improved its removal ability. The TOC removal rate in NF was assessed up to $93 \%$ at Y $=85 \%$ of permeate recovery rate. This result is in concordance with those obtained in some previous studies (Byun et al., 2015; Maryam et al., 2020). 


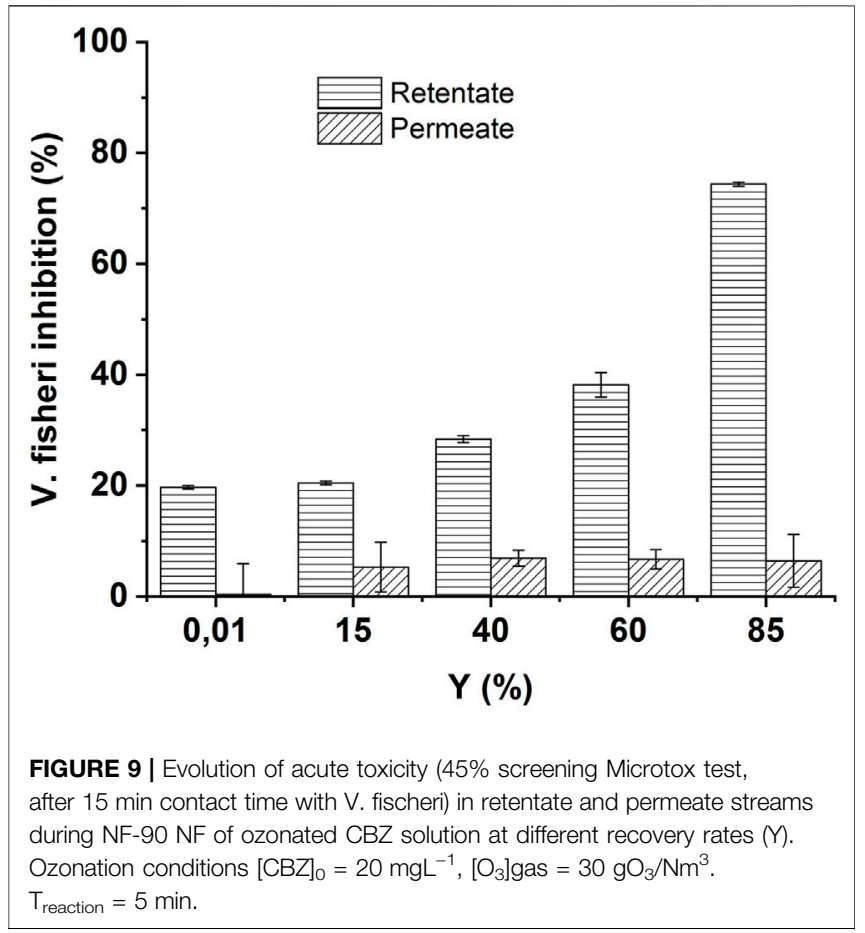

\subsubsection{Carbamazepine By-Products Removal Rate}

Azaïs et al., 2016 have demonstrated that CBZ could be effectively removed from WWTP effluent by NF-90 with rejections rates between 97 and 99\%. To evaluate the impact of a pre-ozonation on NF performances, the removal rate of CBZ ozone-based degradation by-products using an NF-90 membrane was assessed. The removal rate during the experiment as a function of the recovery rate is depicted in SI.

It reveals that NF with NF-90 enables a removal of $100 \%$ of CBZ and its by-products, except for the CBZ by-product II, for which the removal rate was between 80 and 96\%, depending on the recovery rate. The main removal mechanism for these by-products could be steric hindrance given that, for all of them, the molecular weight (MW) (I: 253.1 g.mol-1, BQM: 251.08 g.mol-1, BQD: 267.10 g.mol1, BaQM: 267.10 g.mol-1 and BaQD: 283.07 g.mol-1) is higher than the MWCO (150 g.mol-1) of the NF-90 membrane utilized. The byproduct II is the only kind with a MW (147.06 g.mol-1) smaller than the membrane MWCO and may be responsible for the TOC values in permeate (Figure 8). These results confirm that the NF-90 membrane is suitable to effectively remove the ozone-based degradation by-products of OMPs with relatively low MW.

\subsubsection{Toxicity of Retentate and Permeate Streams in Nanofiltration}

Concomitantly to by-products removal, the toxicity was also assessed in retentate and permeate streams for the different recovery rates. The results are shown in Figure 9.

As the recovery rate increases, the TOC concentration in the retentate stream also increases. At the same time, the concentration in the permeate stream decreases. As expected in accordance with the good removal of the different by-products, the toxicity in the retentate increases, while it decreases in the permeate stream. The low toxicity in the permeate is a logical outcome given that the main transformations by-products suspected to be responsible for such toxicity (BQM, BQD) are almost totally rejected by the NF operation (Figure 9). This result is highly important since it demonstrates that when the ozonation was employed in experimental conditions that increased toxicity, the combination with NF operation made it possible to obtain a water without toxicity in the permeate. The implementation of an additional treatment step after ozonation, such as sand filtration or activated carbon filters, has already demonstrated the capacity to remove OMPs, by-products and toxicity (Margot et al., 2013; Bourguin et al., 2018). The present study shows the efficiency of the combination of ozone with NF operation.

\section{CONCLUSION}

This study aimed to investigate the fate and toxicity of CBZ and its oxidation by-products in a pre-ozonation and NF coupling process. It consisted in monitoring the degradation kinetics of CBZ, establishing the ozone-based degradation chemical pathway and then assessing the removal rate of the identified by-products in the combined NF process.

The results confirmed the high reactivity of CBZ towards ozone, since a CBZ solution of $20 \mathrm{mgL}^{-1}$ was almost completely degraded in the $5 \mathrm{~min}$ of contact time, with a specific transferred ozone dose of $2.48 \mathrm{mgO}_{3} / \mathrm{mgC}$. Nonetheless, the TOC removal rate was only around $12 \%$ after $5 \mathrm{~min}$ of ozonation, confirming the inefficiency of the ozonation process in terms of organic matter mineralization. The link between the toxicity trends and the chemical pathway of CBZ ozonation indicated that the peak of the toxicity appeared concomitantly with the production of the by-products BQM and $\mathrm{BQD}$, demonstrating their relatively high acute toxicity.

In contrast to the ozonation process where only $12 \%$ of TOC was removed, up to $93 \%$ of TOC removal was achieved in NF. This result is consistent with the by-products removal rates, which were around $100 \%$ for all by-products except the CBZ by-product II, which had a MW slightly smaller than the MWCO of the membrane and for which the removal rate was, however, higher than $80 \%$. In addition, since almost all the aromatic by-products were retained by the membrane, very low toxicity was detected in the permeate streams, while retentates toxicity increased significantly with the increasing BQM and BQD concentrations in the retentates.

To sum up, the coupling of NF and ozonation has demonstrated its efficiency in safely removing CBZ and its transformation byproducts. The synergetic effect of this hybrid process can be utilized to eliminate refractory OMPs, thereby helping the design of effective treatment systems for safe and sustainable DWW reuse. Further investigations will concern the impact of pre-ozonated NF retentate recirculation on MBR performance.

\section{DATA AVAILABILITY STATEMENT}

The original contributions presented in the study are included in the article/Supplementary Material, further inquiries can be directed to the corresponding author. 


\section{AUTHOR CONTRIBUTIONS}

ZY made experiments and first writting. JM is principal investigator of the project. GL, FZ, and SB have readen and corrected the manuscript. EP did analytical work.

\section{FUNDING}

The authors acknowledge the French National Agency for Research (ANR) for supporting this study through the convention ANR JCJC 2016 project SAWARE (ANR-16-CE04-0002-01).

\section{REFERENCES}

Andreozzi, R., Marotta, R., Pinto, G., and Pollio, A. (2002). Carbamazepine in Water: Persistence in the Environment, Ozonation Treatment and Preliminary Assessment on Algal Toxicity. Water Res. 36, 2869-2877. doi:10.1016/s00431354(01)00500-0

Azaïs, A., Mendret, J., Cazals, G., Petit, E., and Brosillon, S. (2017). Ozonation as a Pretreatment Process for Nanofiltration Brines: Monitoring of Transformation Products and Toxicity Evaluation. J. Hazard. Mater. 338, 381-393. doi:10.1016/ j.jhazmat.2017.05.045

Azaïs, A., Mendret, J., Gassara, S., Petit, E., Deratani, A., and Brosillon, S. (2014). Nanofiltration for Wastewater Reuse: Counteractive Effects of Fouling and Matrice on the Rejection of Pharmaceutical Active Compounds. Sep. Purif. Techn. 133, 313-327. doi:10.1016/j.seppur.2014.07.007

Azaïs, A., Mendret, J., Petit, E., and Brosillon, S. (2016). Influence of Volumetric Reduction Factor during Ozonation of Nanofiltration Concentrates for Wastewater Reuse. Chemosphere 165, 497-506. doi:10.1016/ j.chemosphere.2016.09.071

Baawain, M. S., Al-Mamun, A., Omidvarborna, H., Al-Sabti, A., and Choudri, B. S. (2020). Public Perceptions of Reusing Treated Wastewater for Urban and Industrial Applications: Challenges and Opportunities. Environ. Dev. Sustain. 22, 1859-1871. doi:10.1007/s10668-018-0266-0

Bader, H., and Hoigné, J. (1981). Determination of Ozone in Water by the Indigo Method. Water Res. 15, 449-456. doi:10.1016/0043-1354(81)90054-3

Bourgin, M., Beck, B., Boehler, M., Borowska, E., Fleiner, J., Salhi, E., et al. (2018). Evaluation of a Full-Scale Wastewater Treatment Plant Upgraded with Ozonation and Biological post-treatments: Abatement of Micropollutants, Formation of Transformation Products and Oxidation By-Products. Water Res. 129, 486-498. doi:10.1016/j.watres.2017.10.036

Braeutigam, P., Franke, M., Schneider, R. J., Lehmann, A., Stolle, A., and Ondruschka, B. (2012). Degradation of Carbamazepine in Environmentally Relevant Concentrations in Water by Hydrodynamic-Acoustic-Cavitation (HAC). Water Res. 46, 2469-2477. doi:10.1016/j.watres.2012.02.013

Byun, S., Taurozzi, J. S., and Tarabara, V. V. (2015). Ozonation as a Pretreatment for Nanofiltration: Effect of Oxidation Pathway on the Permeate Flux. Sep. Purif. Techn. 149, 174-182. doi:10.1016/j.seppur.2015.05.035

Chon, K., Sarp, S., Lee, S., Lee, J.-H., Lopez-Ramirez, J. A., and Cho, J. (2011). Evaluation of a Membrane Bioreactor and Nanofiltration for Municipal Wastewater Reclamation: Trace Contaminant Control and Fouling Mitigation. Desalination 272, 128-134. doi:10.1016/j.desal.2011.01.002

Cirelli, G. L., Consoli, S., Licciardello, F., Aiello, R., Giuffrida, F., and Leonardi, C. (2012). Treated Municipal Wastewater Reuse in Vegetable Production. Agric. Water Manag. 104, 163-170. doi:10.1016/j.agwat.2011.12.011

Clara, M., Strenn, B., Gans, O., Martinez, E., Kreuzinger, N., and Kroiss, H. (2005). Removal of Selected Pharmaceuticals, Fragrances and Endocrine Disrupting Compounds in a Membrane Bioreactor and Conventional Wastewater Treatment Plants. Water Res. 39, 4797-4807. doi:10.1016/j.watres.2005.09.015

Deng, H. (2020a). A Review on the Application of Ozonation to NF/RO Concentrate for Municipal Wastewater Reclamation. J. Hazard. Mater. 391, 122071. doi:10.1016/j.jhazmat.2020.122071

\section{ACKNOWLEDGMENTS}

The authors are thankful to Loubna Karfane Atfane for providing technical support.

\section{SUPPLEMENTARY MATERIAL}

The Supplementary Material for this article can be found online at: https://www.frontiersin.org/articles/10.3389/fenvc.2021.798785/ full\#supplementary-material

Deng, H. (2020b). Ozonation Mechanism of Carbamazepine and Ketoprofen in RO Concentrate from Municipal Wastewater Treatment: Kinetic Regimes, Removal Efficiency and Matrix Effect. Sci. Total Environ. 717, 137150. doi:10.1016/j.scitotenv.2020.137150

Dodd, M. C., Buffle, M.-O., and von Gunten, U. (2006). Oxidation of Antibacterial Molecules by Aqueous Ozone: Moiety-specific Reaction Kinetics and Application to Ozone-Based Wastewater Treatment. Environ. Sci. Technol. 40, 1969-1977. doi:10.1021/es051369x

Doll, T. E., and Frimmel, F. H. (2005). Removal of Selected Persistent Organic Pollutants by Heterogeneous Photocatalysis in Water. Catal. Today 101, 195-202. doi:10.1016/j.cattod.2005.03.005

Dong, H., Yuan, X., Wang, W., and Qiang, Z. (2016). Occurrence and Removal of Antibiotics in Ecological and Conventional Wastewater Treatment Processes: A Field Study. J. Environ. Manage. 178, 11-19. doi:10.1016/j.jenvman.2016.04.037

Dubowski, Y., Alfiya, Y., Gilboa, Y., Sabach, S., and Friedler, E. (2020). Removal of Organic Micropollutants from Biologically Treated Greywater Using Continuous-Flow Vacuum-UV/UVC Photo-Reactor. Environ. Sci. Pollut. Res. 27, 7578-7587. doi:10.1007/s11356-019-07399-7

El Kateb, M., Trellu, C., Darwich, A., Rivallin, M., Bechelany, M., Nagarajan, S., et al. (2019). Electrochemical Advanced Oxidation Processes Using Novel Electrode Materials for Mineralization and Biodegradability Enhancement of Nanofiltration Concentrate of Landfill Leachates. Water Res. 162, 446-455. doi:10.1016/j.watres.2019.07.005

Gogoi, A., Mazumder, P., Tyagi, V. K., Tushara Chaminda, G. G., An, A. K., and Kumar, M. (2018). Occurrence and Fate of Emerging Contaminants in Water Environment: A Review. Groundwater Sust. Dev. 6, 169-180. doi:10.1016/ j.gsd.2017.12.009

Gude, V. G. (2017). Desalination and Water Reuse to Address Global Water Scarcity. Rev. Environ. Sci. Biotechnol. 16, 591-609. doi:10.1007/s11157-0179449-7

Guillossou, R., Le Roux, J., Brosillon, S., Mailler, R., Vulliet, E., Morlay, C., et al. (2020). Benefits of Ozonation before Activated Carbon Adsorption for the Removal of Organic Micropollutants from Wastewater Effluents. Chemosphere 245, 125530. doi:10.1016/j.chemosphere.2019.125530

Hu, L., Martin, H. M., Arce-Bulted, O., Sugihara, M. N., Keating, K. A., and Strathmann, T. J. (2009). Oxidation of Carbamazepine by $\mathrm{Mn}$ (VII) and Fe(VI) Reaction Kinetics and Mechanism. Environ. Sci. Technol. 43, 509-515. doi:10.1021/es8023513

Huber, M. M., Canonica, S., Park, G.-Y., and von Gunten, U. (2003). Oxidation of Pharmaceuticals during Ozonation and Advanced Oxidation Processes. Environ. Sci. Technol. 37, 1016-1024. doi:10.1021/es025896h

Hübner, U., Seiwert, B., Reemtsma, T., and Jekel, M. (2014). Ozonation Products of Carbamazepine and Their Removal from Secondary Effluents by Soil Aquifer Treatment - Indications from Column Experiments. Water Res. 49, 34-43. doi:10.1016/j.watres.2013.11.016

Ikehata, K., Jodeiri Naghashkar, N., and Gamal El-Din, M. (2006). Degradation of Aqueous Pharmaceuticals by Ozonation and Advanced Oxidation Processes: A Review. Ozone: Sci. Eng. 28, 353-414. doi:10.1080/01919510600985937

Iorhemen, O., Hamza, R., and Tay, J. (2016). Membrane Bioreactor (MBR) Technology for Wastewater Treatment and Reclamation: Membrane Fouling. Membranes 6, 33. doi:10.3390/membranes6020033 
Javier Benitez, F., Acero, J. L., Real, F. J., and Roldán, G. (2009). Ozonation of Pharmaceutical Compounds: Rate Constants and Elimination in Various Water Matrices. Chemosphere 77, 53-59. doi:10.1016/j.chemosphere.2009.05.035

Kellis, M., Kalavrouziotis, I. K., and Gikas, P. (2013). Review of Wastewater Reuse in the Mediterranean Countries, Focusing on Regulations and Policies for Municipal and Industrial Applications. Glob. NEST J. 15, 333-350. doi:10.30955/gnj.000936

Lan, Y., Groenen-Serrano, K., Coetsier, C., and Causserand, C. (2018). Nanofiltration Performances after Membrane Bioreactor for Hospital Wastewater Treatment: Fouling Mechanisms and the Quantitative Link between Stable Fluxes and the Water Matrix. Water Res. 146, 77-87. doi:10.1016/j.watres.2018.09.004

Le, T. X. H., Nguyen, T. V., Amadou Yacouba, Z., Zoungrana, L., Avril, F., Nguyen, D. L., et al. (2017). Correlation between Degradation Pathway and Toxicity of Acetaminophen and its By-Products by Using the Electro-Fenton Process in Aqueous media. Chemosphere 172, 1-9. doi:10.1016/j.chemosphere.2016.12.060

Le, T. X. H., Nguyen, T. V., Yacouba, Z. A., Zoungrana, L., Avril, F., Petit, E., et al. (2016). Toxicity Removal Assessments Related to Degradation Pathways of Azo Dyes: Toward an Optimization of Electro-Fenton Treatment. Chemosphere 161, 308-318. doi:10.1016/j.chemosphere.2016.06.108

Luo, Y., Guo, W., Ngo, H. H., Nghiem, L. D., Hai, F. I., Zhang, J., et al. (2014). A Review on the Occurrence of Micropollutants in the Aquatic Environment and Their Fate and Removal during Wastewater Treatment. Sci. Total Environ. 473474, 619-641. doi:10.1016/j.scitotenv.2013.12.065

Lyu, S., Chen, W., Zhang, W., Fan, Y., and Jiao, W. (2016). Wastewater Reclamation and Reuse in China: Opportunities and Challenges. J. Environ. Sci. 39, 86-96. doi:10.1016/j.jes.2015.11.012

Majumder, A., Gupta, B., and Gupta, A. K. (2019). Pharmaceutically Active Compounds in Aqueous Environment: A Status, Toxicity and Insights of Remediation. Environ. Res. 176, 108542. doi:10.1016/j.envres.2019.108542

Margot, J., Kienle, C., Magnet, A., Weil, M., Rossi, L., de Alencastro, L. F., et al. (2013). Treatment of Micropollutants in Municipal Wastewater: Ozone or Powdered Activated Carbon? Sci. Total Environ. 461-462, 480-498. doi:10.1016/j.scitotenv.2013.05.034

Maryam, B., Buscio, V., Odabasi, S. U., and Buyukgungor, H. (2020). A Study on Behavior, Interaction and Rejection of Paracetamol, Diclofenac and Ibuprofen (PhACs) from Wastewater by Nanofiltration Membranes. Environ. Techn. Innovation 18, 100641. doi:10.1016/j.eti.2020.100641

McDowell, D. C., Huber, M. M., Wagner, M., von Gunten, U., and Ternes, T. A. (2005). Ozonation of Carbamazepine in Drinking Water: Identification and Kinetic Study of Major Oxidation Products. Environ. Sci. Technol. 39, 8014-8022. doi:10.1021/es0500431

Ouali, S., Loulergue, P., Biard, P. F., Nasrallah, N., and Szymczyk, A. (2020). Ozone Compatibility with Polymer Nanofiltration Membranes. J. Membr. Sci. 618, 118656. doi:10.1016/j.memsci.2020.118656

Papageorgiou, A., Stylianou, S. K., Kaffes, P., Zouboulis, A. I., and Voutsa, D. (2017). Effects of Ozonation Pretreatment on Natural Organic Matter and Wastewater Derived Organic Matter - Possible Implications on the Formation of Ozonation By-Products. Chemosphere 170, 33-40. doi:10.1016/ j.chemosphere.2016.12.005

Po, M., Nancarrow, B. E., Leviston, Z., Porter, N. B., Syme, G. J., and Kaercher, J. D. (2005). Predicting Community Behaviour in Relation to Wastewater Reuse. What Drives Decisions to Accept or Reject?. Perth: CSIRO

Pohl, J., Golovko, O., Carlsson, G., Eriksson, J., Glynn, A., Örn, S., et al. (2020). Carbamazepine Ozonation Byproducts: Toxicity in Zebrafish (Danio rerio) Embryos and Chemical Stability. Environ. Sci. Technol. 54, 2913-2921. doi:10.1021/acs.est.9b07100

PubChem (2020). Carbamazepine. Perth: CSIRO. Available at: : https://pubchem. ncbi.nlm.nih.gov/compound/2554 (Accessed on Aug 24, 2020).
Rekhate, C. V., and Srivastava, J. K. (2020). Recent Advances in Ozone-Based Advanced Oxidation Processes for Treatment of Wastewater- A Review. Chem. Eng. J. Adv. 3, 100031. doi:10.1016/j.ceja.2020.100031

Rosal, R., Rodríguez, A., Perdigón-Melón, J. A., Mezcua, M., Hernando, M. D., Letón, P., et al. (2008). Removal of Pharmaceuticals and Kinetics of Mineralization by $\mathrm{O} 3 / \mathrm{H} 2 \mathrm{O} 2$ in a Biotreated Municipal Wastewater. Water Res. 42, 3719-3728. doi:10.1016/j.watres.2008.06.008

Snyder, S. A., Wert, E. C., Rexing, D. J., Zegers, R. E., and Drury, D. D. (2006). Ozone Oxidation of Endocrine Disruptors and Pharmaceuticals in Surface Water and Wastewater. Ozone: Sci. Eng. 28, 445-460. doi:10.1080/ 01919510601039726

Ternes, T. A., Stüber, J., Herrmann, N., McDowell, D., Ried, A., Kampmann, M., et al. (2003). Ozonation: a Tool for Removal of Pharmaceuticals, Contrast media and Musk Fragrances from Wastewater? Water Res. 37, 1976-1982. doi:10.1016/s0043-1354(02)00570-5

Vatankhah, H., Murray, C. C., Brannum, J. W., Vanneste, J., and Bellona, C. (2018). Effect of Pre-ozonation on Nanofiltration Membrane Fouling during Water Reuse Applications. Sep. Purif. Techn. 205, 203-211. doi:10.1016/ j.seppur.2018.03.052

Vogna, D., Marotta, R., Andreozzi, R., Napolitano, A., and d'Ischia, M. (2004). Kinetic and Chemical Assessment of the UV/H2O2 Treatment of Antiepileptic Drug Carbamazepine. Chemosphere 54, 497-505. doi:10.1016/s0045-6535(03) 00757-4

Völker, J., Stapf, M., Miehe, U., and Wagner, M. (2019). Systematic Review of Toxicity Removal by Advanced Wastewater Treatment Technologies via Ozonation and Activated Carbon. Environ. Sci. Technol. 53, 7215-7233. doi:10.1021/acs.est.9b00570

Wert, E. C., Rosario-Ortiz, F. L., and Snyder, S. A. (2009). Effect of Ozone Exposure on the Oxidation of Trace Organic Contaminants in Wastewater. Water Res. 43, 1005-1014. doi:10.1016/j.watres.2008.11.050

Yacouba, Z. A., Mendret, J., Lesage, G., Zaviska, F., and Brosillon, S. (2021). Removal of Organic Micropollutants from Domestic Wastewater: The Effect of Ozone-Based Advanced Oxidation Process on Nanofiltration. J. Water Process Eng. 39, 101869. doi:10.1016/j.jwpe.2020.101869

Yu, W., Liu, T., Crawshaw, J., Liu, T., and Graham, N. (2018). Ultrafiltration and Nanofiltration Membrane Fouling by Natural Organic Matter: Mechanisms and Mitigation by Pre-ozonation and $\mathrm{pH}$. Water Res. 139, 353-362. doi:10.1016/j.watres.2018.04.025

Zhang, H., He, Q., Luo, J., Wan, Y., and Darling, S. B. (2020). Sharpening Nanofiltration: Strategies for Enhanced Membrane Selectivity. ACS Appl. Mater. Inter. 12 (36), 39948-39966. doi:10.1021/acsami.0c11136

Conflict of Interest: The authors declare that the research was conducted in the absence of any commercial or financial relationships that could be construed as a potential conflict of interest.

Publisher's Note: All claims expressed in this article are solely those of the authors and do not necessarily represent those of their affiliated organizations, or those of the publisher, the editors and the reviewers. Any product that may be evaluated in this article, or claim that may be made by its manufacturer, is not guaranteed or endorsed by the publisher.

Copyright (C) 2021 Yacouba, Lesage, Mendret, Zaviska, Petit and Brosillon. This is an open-access article distributed under the terms of the Creative Commons Attribution License (CC BY). The use, distribution or reproduction in other forums is permitted, provided the original author(s) and the copyright owner(s) are credited and that the original publication in this journal is cited, in accordance with accepted academic practice. No use, distribution or reproduction is permitted which does not comply with these terms. 